\title{
El tiempo en Aristóteles
}

\author{
J. D. Vial Larraín
}

ABSTRACT (Time in Aristotle)

According to Heidegger, the Aristotelian exegesis of time is decisive in the history of western European metaphisics. In giving the aspect of «no...» a priviledged position, occidental metaphysics forgot all about the originat state of existence and centered its thoughts upon the "permanent presente».

However, the Physics of Aristotle, a great aporia as far as the factor of time is concerned, does not give us the true key to the subject. It is to be found in the Metaphysics of Aristotle, where there is apparently no such omission of existence in the Heideggerian sense of the term. This work presents time not only in connection with matter, but also and especially with intelligence and thus reveals the identity of the question of existence wih the task of thinking.

\section{I}

En su libro sobre la metafísica vista desde la Crítica de la Razón Pura, elaborado a parejas con su obra fundamental, Ser y Tiempo, Heidegger escribió: «La esencia del tiempo fue expuesta de manera decisiva para la historia posterior de la metafisica por Aristóteles» (Kant y el Problema de la Metajísica, p. 44).

Esa exposición aristotélica del tiempo, a la que mirara como decisiva para la metafísica -añadió, sin embargo- no ofrece ninguna respuesta (la palabra «ninguna» está subrayada en el originai) para la cuestión clave de la metafísica misma. Dicha cuestión sería aquella que la metafísica eluđió al constituirse. Pero que ia eludió, justamente, para poder constituirse. En tal sentiđo, ésta no habría sido una omisión reparable, excusable o irrelevante, sino un verdadero pecado original ligado a su propia naturaleza. 
En la tesis de Heidegger habría, a primera vista, una cierta ambigüedad. La carencia completa de respuesta para una cuestión que ella misma, en parte, habria provocado, o por lo menos de la que pudiera considerarse decisivamente responsable, pareciera un signo negativo de la exégesis aristotélica del tiempo, algo así como lo que para la ciencia sería una hipótesis infecunda. Pero como esa carencia va a resultar decisiva en el surgimiento de la metafísica y para su historia ulterior, habria que estimar que esa negatividad realmente ha sido una condición de posibilidad. El pecado original seria, entonces, una «feliz culpa», para usar palabras de Lutero.

La cuestión clave de la metafísica, que la metafísica eluđiera y olvi. dara, según Heidegger, es justamente aquella que el mismo Heidegger ha situado en el foco de su propio pensamiento. Es la pregunta por el sentido del ser, por el ámbito donde el ser se manifiesta, viene a la luz, acontece en el ente y es comprendido por el hombre. Es la pregunta por la verdad del ser. La metafísica la habría olvidado, pero ella estaría irremisiblemente oculta entre los pliegues de la misma metafísica, dándole su propio sentido.

El olvido del ser en el que la metafísica ha incurrido obligaria, entonces, piensa Heidegger, a superar la metafísica. Pero esta superación, Uberwindung, nada tiene que ver con un dejar atrás o un eliminar la metafísica, en el generalizado sentido del positivismo del que participara el propio Nietzsche y que el Círculo de Viena intentó codificar en nuestro siglo. La superación de la metafísica es la forma de hacerse cargo verdaderamente, justo de eso que la metafísica olvidó, de llegar a pensar aquello que permitió constituirla y que ella misma hubo de dejar a sus espaldas, de lo que se manifiesta como un destino que Heidegger ha Ilamado el «destino del ser». El olvido es, pues, un destino; la negatividad, una posibilidad.

Parafraseando un poco a Heidegger, pudiera quizá decirse que la metafísica ha sido el velo del ser, velo que, para Heidegger es, precisamente, la nada. El olvido esencial de la metafísica sería la nada. Apretando las palabras: la metafísica sería nada. Pero en un sentido absolutamente distinto al que pudiera atribuirse a esas palabras en una fórmula positivista que intentara expresar así lo que para el positivismo no es sino carencia de sentido de la metafísica. La metafísica poseería sentido. en el pensamiento de Heidegger, justamente, por virtud de esa nada que es un olvido, un velo, una posibilidad.

Hegel dijo en la Ciencia de la Lógica (Prefacio) que un pueblo culto sin metafísica ofrecería un espectáculo tan asombroso como el de un templo sin santuario, lo que es una ironía terrible, porque un templo sin santuario, en rigor, no es un templo; o es un templo desafectado, abandonado, vacío. Hegel ha sido, para Heidegger, el último gran meta- 
físico de Occidente. Y, más que eso, aquel en quien la metafísica habría hallado su consumación. $Y$ en este preciso sentido Hegel fue, segura. mente, el gran interlocutor de Heidegger. Más que Nietzsche y que cualquiera de los presocráticos; y más que Kant, a quien en rigor no habría que mirar como a un interlocutor de Heidegger, sino más bien como aquel de quien Heidegger proviene, en donde las estructuras fundamentales de su pensamiento se forjaron.

Consideremos la idea de una consumación de la metafísica que en el pensamiento de Hegel habría tenido lugar. Esta idea cabe entenderla a la luz del parágrafo 13 de la Enciclopedia de las Ciencias Filosóficas del propio Hegel. Hegel dice, ahí, que la filosofía que es última en el tiempo es, a la vez, resultado de todas las precedentes. Y, por consiguiente, contiene los principios de todas. En tal forma, no clausura, sino que abre y renueva una historia.

En un trasunto de una misma idea, Heidegger, en su conferencia sobre El Principio de Identidad, dijo que, dondequiera y comoquiera que intentemos pensar, pensamos en el espacio de juego de la tradición. La superación de la metafísica viene a ser, entonces, una apertura del pensamiento al origen de la metafísica. Ahora bien, éste no puede ser descubierto sino preguntando por el sentido del ser. Pregunta que ha de ser desarrollada a través de una historia, de una historia remontada de la ontología y, precisamente porque hay que remontarla, porque hay que regresar a sus principios, esta historia toma los caracteres de una «destrucción», según la célebre palabra del sexto parágrafo de Ser y Tiempo. Tal «destrucción de la historia de la ontologia» tampoco tiene un sentido negativo, como si se tratara nada más que de "sacudirse la tradición», según dijera Heidegger, sino que es, por el contrario, la forma de actualizarla, y aun diría: de gestarla. Por consiguiente, éste es el verdadero sentido de la historicidad.

La superación de la metafísica, en consecuencia, por una parte sería el velo roto -el desvelamiento- por un pensar todavía venidero que recupera del olvido la posibilidad misma de la metafísica. Así entendido, el "olvido del ser» de que habla Heidegger, pareciera recoger el sentido de aquello que Kant llamara «ilusión trascendental» que sería, justamente, el espacio donde la metafísica clásica se constituiría. Desde este punto de vista, la superación de la metafísica pudiera considerarse una tesis inscrita dentro del proyecto kantiano de una dialéctica trascendental.

Por otra parte, es sabido que el momento inicial de la dialéctica - ahora en el sentido que esta noción toma en la Lógica de Hegel- está en lo que para Hegel es la identidad de ser y nada en un momento de inicial indeterminación, llamado a consumarse en la forma de un saber absoluto. Este saber absoluto es la filosofía que se construye como una constante en la forma de círculo de círculos, de un último círculo, de un saber último. 
El "olvido del ser" ¿es una ilusion? ¿Radica en tal olvido la posibi. lidad de la metafísica, como en la «ilusión trascendental» de la dialéctica kantiana? ¿Es la "destrucción de la historia de la ontología" la clave de una dialéctica en el estilo de la dialéctica de Hegel?

Diría, más bien, que la superación de la metafísica --desvelamiento de un olvido y destrucción de una historia- acusa la formidable tentativa de Heidegger para anudar los poderosos hilos de la dialéctica como fuera concebiđa por Kant, a partir de una itusión y de la dialéctica cuyo principio viera Hegel en la indeterminación del ser y la nada. $Y$, en esta forma, tal anudar, es un reanudar la profunda energia del idealismo alemán.

Pcro la confrontación de Kant y Hegel, del fondo del pensamiento que uno y otro expresaron como dialéctica, que en el pensamiento de Heidegger tendría lugar, cobra todo su sentido si se reconoce el transfondo fundamental sobre el que está construida. Esta es la dialéctica de Platón: vale decir, la dialéctica en su concepción original. Kant y Hegel vendrán a situarse en el espacio de juego de Platón.

Ahora bien, en el pensamiento platónico, a juicio de Heidegger, el ser estaría velado y olvidado ya en las Ideas. Y, por otra parte, la verdad estaría planteada como desvelamiento y victoria sobre el olvido, como la exégesis de la alegoría de la caverna lo da a entender. Así, pues, la superación de la metafísica asumiría la filosofía a lo menos desde Platón hasta Hegel; y desđe antes de Platón (presocráticos) y después de Hegel (Nietzsche). La "destrucción» de la ontología intentaría recuperar sus principios y actualizarlos. La última filosofía sería la de Heidegger.

\section{II}

Una exposición acerca del tiempo en la flosofía de Atistóteles no podría haber eludido el pensamiento de Heidegger cuyo nervio parece ser, justamente, la iđea de tiempo, proyectada sobre la fundamental tesis de Aristóteles sobre la multiplicidad de sentidos en los que se dice el ser. Volvamos, pues, al punto de partida de esta exposición: la significación decisiva para la metafísica de la esencia del tiempo en la exégesis de Aristóteles. El olvido del ser que embargaría la metafísica, determinándola precisamente como un ocultamiento, estaría íntimamente ligado a la esencia del tiempo concebida por Aristóteles. La exégesis aristotélica del tiempo privilegiaría el "ahora» y, por consiguiente, el presente. La metafísica occidental -Aristóteles inclusive- concebiría el ser como presencia, y como presencia permanente.

Desde el eidos platónico a todas las formas de representación propias de la normatividad subjetiva de la conciencia que han regido la meta- 
física, el sentido del ser estaría dado en las ideas de presente, presencia, permanencia y lo que en ellas cabe leer es una concepción del tiempo que fuera la de Aristóteles. Dicha temporalidad no podría desbaratarse, ni siquiera ponerse en cuestión por una simple maniobra lógica de la inteligencia. El tiempo articula la misma existencia humana y, en consecuencia, la comprensión del ser que le es esencial. De ahí la necesidad de una analítica de la existencia humana, en un proyecto determinado por Ios extremos ser y tiempo, o tiempo y ser, que fue la principal empresa intelectual cumplida por Heidegger.

Heidegger ha dicho que la Fisica de Aristóteles es el libro fundamental de la filosofía de Occidente (Qué es y cómo se determina la Physis) y ciertamente la exégesis del tiempo a la que atribuye tan decisiva significación para la metafísica es la recogida en ese libro. Esa exégesis, en efecto. resonará nítidamente a lo largo de la filosofía occidental desde las Confesiones de San Agustín, a los Principios de Descartes, a la Estética de Kant, a la Lógica de Hegel, hasta Bergson y el propio Heidegger. De paso téngase, sin embargo, en cuenta, que ella aparece en la lógica de Hegel cuando se habla de mecánica, en los Principios de Descartes cuando se habla de física y en la Crítica de Kant a partir de la físiconmatemática.

Pero la Física es, más bien, una gran aporética del tiempo. En ella se dispara en todas direcciones, en lo que es, por momentos, un verdadero laberinto cuyos ecos, por cierto, resuenan hasta la filosofía contemporánea. Sin embargo, el pensamiento propio de Aristóteles adquiere toda su estatura en otro lugar: en la Metafisica. Y en ésta no parece que el sentido del ser esté olvidado, ni que el ser aparezca como presencia permanente.

Heidegger ha dicho reiteradamente que el punto de partida de su filosofía fue su contacto inicial con Aristóteles. Así comienza recordándolo en el escrito que dictara a Jean Beaufret, recientemente editado. Pues bien, ahí leyó Heidegger la cuestión del ser. Los recursos metódicos para su investigación hubo de sacarlos, sin embargo, de la filosofía académica de su medio, que era la Fenomenología de Husserl. En la Fenomenología la cuestión del ser debía ser leída como posición de una conciencia constituyente. Entonces caía de su peso que el ser fuera entendido como presencia. Pero Heidegger parece haber aplicado retrospectivamente esta respuesta a toda la metafísica. Y pudo, entonces, reconocer en la Física de Aristóteles la confirmación de que el ser estaba concebido como pre. sencia a una con la concepción del tiempo como ahora. Y en una y otra forma el sentido del ser estaría "olvidado».

Si eso, efectivamente, puede ser leído en la Fisica pienso que no es lo que la Metafísica establece. Lo que en ella puede leerse es justamente eso que Heidegger redescubrió: la cuestión del sentido del ser. Y la ener. geia, que es la respuesta aristotélico a esa cuestión, no significa "presen" 
cia», ni está ligada a un "ahora» del tiempo. Significa, más bien, lo que para Heidegger sería la tarea y la obra del pensar.

La destrucción de la historia de la ontología permitió a Heidegger redescubrir la metafísica de Aristótcles. No obstante, su poderosa mirada parece haber sufrido algo así como un efecto de desviación -dijérase, un olvido del ser-consecuencia del peso que sobre ella ha debido ejercer su trađición más próxima, aquella que está en Husserl y en Hegel, en Kant y en Leibniz, pero que probablemente habría que explorar en Boehme y en Eckhart, en ja mística germánica que viera en la nada un primer principio.

\section{III}

El foco del pensamiento de Aristóteles, seguramente, es la sustancia. El Libro séptimo de la Metafísica lo deja bien en ciaro. Y también es claro que la sustancia debe ser entendida en términos de un «esto», de un "aquí», de un «ahora» y en ellos el presente, la presencia y una estabilidad concebida como permancncia, son Ias ideas dominantes. El Organon, el instrumento del pensar de que Aristóteles se sirve, desde sus líneas iniciales, pone de relieve la sustancia en la base de las categorías, en la clave de la estructura predicativa del pensamiento, en la figura que toman la experiencia y las cosas.

Es un hecho, también, bien característico del pensar aristotélico que. primordialmente, la sustancia de que en él se habla es la sustancia física caracterizada por el movimiento y el tiempo. Por supuesto, entonces, que la Física es un libro de base.

Lo que de ninguna manera resulta claro es que pueda considerarse la Física como la versión definitiva del pensamiento de Aristóteles acerca de la sustancia y el tiempo. La verdad es, probablemente, la contraria. Lo que en la Física puede leerse es, más bien, el planteo de lo que en la Metafísica será puesto en cuestión. En efecto, desde luego el Libro VII de la Metafisica es, eminentemente, una aporética de la sustancia. Ahí la sustancia es la pregunta de Aristóteles. $Y$ esta pregunta está hecha desde el punto de vista del sentido del ser. El capítulo inicial de este libro to dice de manera bien rotunda.

La cuestión que desde antiguo, y ahora, y siempre, se ha planteado, la cuestion que es siempre materia de constante duda, ¿qué es el ente? —dice Aristóteles- equivale a ¿qué es la sustancia? La pregunta de Aristóteles es por el ente en la multiplicidad de sus sentidos, por los sentidos diversos en los que el ente puede ser leído, y está dirigida, precisamente, al sentido fundamental en el que el propio Aristóteles la ha leído: hacia la sustancia. 
A todo lo largo del Libro ViI, seguramente el más extenso de la Metafísica y perteneciente a lo que era para Jaeger la columna vertebral de la obra, lo que se desarrolla no es otra cosa que la cuestión de la sustancia, o la puesta en cuestión de la sustancia, en el más puro estilo diaporético propio del pensar de Aristóteles. De capítulo en capítulo se proponen interpretaciones distintas, puntos de vista que se contraponen en todos los niveles de comprensión. La forma, el sustrato, la composición, lo concreto, lo universal, ¿de qué manera operan en lo que es la sustancia? Y el resultado de esta exploración diaporética no es sino eso: una aporética. ¿Qué otra cosa pensar cuando en el capítulo final de este Libro VII Aristóteles declara que para llegar a saber qué cosa es la sustancia es necesario arrancar de otro principio? (1.041 a. 6). El principio mismo del ente fundamental postulado no solamente por otros filo. sofos, sino por el propio Aristóteles, no se conoce. Un nuevo principio ha de ser propuesto. El sentido del ser queda abierto.

Aristóteles propone, entonces, entender la sustancia como «un principio y una causas (1.041 a. 9) y esto significa asistir al llegar a ser o al ser producido del ente mismo por la configuración de la materia. La sustancia viene a ser, entonces, el movimiento sustancial que se desarrolla entre la materia y la forma.

El tratado sobre cl tiempo de la Física de Aristóteles es otra gran aporética encabezada por la cuestión de si el tiempo realmente existe. El pasado ya no existe, el futuro todavía no y el «ahora» no es una parte del tiempo, diría Aristóteles (218, a. 7). Cabe preguntar, pues, si el tiempo es el mismo, o si no es el mismo; si el tiempo es continuo o es discreto; si cabe ver en él un eslabón o un límite; si el tiempo es eminentemente destructor o si cabe considerarle, más bien, desde el llegar a ser. Todas estas cuestiones, y otras, son examinadas en la más penetrante e influyente fenomenología del tiempo jamás escrita quizá.

Ahora bien, la vía por donde Aristóteles despejará en la Física la cuestion del tiempo, es el movimiento. En el que Goldschmidt ha llamado un «texto memorable» donde puede leerse «el más antiguo relato doxográfico acerca del tiempos (Temps Physique et Temps Tragique chez Aristote) Aristóteles of rece una breve y sustancial sintesis que puede teducirse a tres tajantes fórmulas: 1. El tiempo «es el movimiento del todo» (218, a. 35). 2. El tiempo es «la esfera en sí misma» $(218$, b). 3. El tiempo es "movimiento" $(218$, b. 8 ). Ahí estatían expresados el pensamiento de Platón y los pitagóricos y sentadas las bases sobre las cuales el propio Aristóteles pensará el tiempo.

La posteridad hará suyo ese planteo, lo prolongará y ampliará dentro de un ancho espectro que va desde los escépticos hasta Plotino y resonará más tarde en Newton y Kant. Heidegger muestra en Ser y Tiempo cómo Hegel lo recoge casi a la letra en la Lógica y en la Enciclopedia y 
Owen dice que los argumentos aristotélicos son una fuente clásica para filósofos e historiadores de la ciencia, que ellos «a través de Agustín continúan ejercitando a filósofos posteriores como Wittgenstein" y que sus problemas "son con frecuencia los nuestros» (Aristotle on Time).

Pues bien, sobre la ancha superficie horizontal de esa bullente aporética del tiempo que hay en la Física parecen insinuarse dos direcciones, dos impulsos verticales que no llegan a cerrarse, que más bien se alzan en una espiral abierta. Uno, fundamental, relaciona el tiempo con el movimiento; por aquí pasará el pensamiento central de Aristóteles. El otro relaciona el tiempo con la inteligencia y es en esta dirección que el pensamiento de Aristóteles alcanzará su mayor altura. La Física no ofrece una teoría, sino una exploración aporética acerca de estas cuestiones. Así, la relación entre movimiento y tiempo es bien vacilante. El tiempo no es movimiento, pero no existe sin el movimiento: ni movimiento, ni independiente del movimiento. La salida parece estar en la noción de medida $y$, específicamente, de número, que conduce a la definición aristotélica: el tiempo es «el número del movimiento según un antes y un despućs» (219 b). Pero ese «antes» y «despućs» apunta más bien a una relación espacial y, por otra parte, Aristóteles llegará a decir que el tiempo mide al movimiento tanto como el movimiento mide al tiempo $(223, b .15)$. Pareciera necesario, entonces, acudir a la otra relación -que, en la Física, sin embargo, se insinúa de paso- la relación tiempo-inteligencia. Porque si el tiempo mide el movimiento, cabe preguntar quién mide al tiempo mismo y desde dónde lo hace. La Física menciona, entonces, el alma y, dentro de ella, específicamente, a la inteligencia. El tiempo mediría el movimiento, numerándolo en una escala de "antes» y «después», pero el tiempo mismo, a su vez, estaría medido por la inteligencia.

Por qué, cómo esto tiene lugar, đe qué modo y en qué orden tiene lugar este ir y venir de reciprocidades, éstas no son cosas que la Fisica aclare, sino que las deja planteadas. La ciencia por Aristóteles buscada y cuyo registro está en las páginas de la Metafisica, llevará ese pensa* miento en estado naciente de la Física a alcanzar toda su estatura. Aquí la espiral se cierra, el pensamiento alcanza ese equilibrio que es la teoría. Desde el nivel primario de la sustancia física, a la función del movi. miento y de éste a la medida del tiempo, hay un salto esencial, un paso a la metafísica en donde ya no hay privilegio ni de la presencia, ni del ahora, pero donde la presencia y el ahora hallan su sentido.

Un análisis minucioso de este asunto obliga a regresar a la Metafísica de Aristóteles, a su unidad, a su sentido, a su coherencia global. No es la oportunidad para intentarlo, pero pensamos que, en particular dos tesis metafísicas de Aristóteles dan la clave final del tiempo y el movi. miento. Ellas son, primera, la energeia como perfección y primacía que rige la transitoriedad discontinua del tiempo y el movimiento y, scgunda, 
la inteligencia como plenitud del acto, de la que penden todo tiempo y movimiento, del Cielo y la Naturaleza.

Un desarrollo continuo y coherente del pensamiento de Aristóteles que pregunta por la sustancia y que investiga su estructura a través del movimiento en el tiempo desde el punto de vista del ser y su sentido, remite a esas tesis. Es desde ahí que realmente se constituye la metafísica y se esclarece la esencia del tiempo. 